\title{
Transport infrastructure indicators for assessing the social comfort of the urban environment
}

\author{
Natalia Martynova ${ }^{1 *}$ and Valentina Budarova ${ }^{1}$ \\ ${ }^{1}$ Industrial University of Tyumen, 625001, Tyumen city, Russia
}

\begin{abstract}
Cities are a complex social institution. A special feature of cities is the development of engineering and transport infrastructure. In this article, to assess the state of the urban agglomeration, the transport system of the city is considered as an indicator of social comfort. As part of the support, control and management of the urban environment, administrative authorities use information technologies that are implemented using geographical information systems (GIS). These GIS take into account all indicators of social comfort, which are based on spatial data about the urban environment. From this, we present the concept of an urban environment data management model for public authorities. The model is based on geoinformation systems. Since the geoinformation analysis allows you to create thematic maps of the urban environment with their subsequent assessment and calculation of indicators of social comfort. For this purpose, an analysis algorithm is presented for the main indicators of transport infrastructure assessment. Thus, this study provides an opportunity to assess the state of the city model and set goals for the development of urban transport networks to increase the level of social comfort of the population.
\end{abstract}

\section{Introduction}

Indicators of the quality of life of citizens, economic factors and generally comfortable living conditions, the development of the urban agglomerate are the main objectives of creating a comfortable urban environment. The concept of a city includes an artificially created environment in a certain territory, the purpose of which is to meet individual needs for basic life resources, including social, cultural and household needs, including security, communication and personal development at a decent level.

Urban living conditions introduce the term "social comfort", which is revealed in the work Sapena et al. [1]. The semantic meaning implies that the General level of citizens ' needs should reach the indicators of satisfaction and quality of life, what is shown Sapena et al. [1]. Indicators of social comfort consist of elements of the urban environment:

- population;

- density indicators (population, buildings);

* Corresponding author: natali.cherdanceva@mail.ru 
- economic development of the territory;

- ecological state of the environment;

- natural and climatic conditions;

- social development;

- transport and engineering infrastructure;

- and others.

Among these indicators, transport and engineering infrastructure is an important element for a comprehensive assessment of the city and its territory development [2]. In General, the development of transport and engineering infrastructure in urban planning consists in:

- development of the urban environment as a transport center with an increase in logistics and commercial cargo transportation;

- development of economic flows;

- development of the urban agglomeration through new construction and reconstruction of engineering and transport infrastructure facilities.

The network of roads, main streets and alleys are the city-forming element of the city, by means of which districts and social centers are connected. A study was conducted on this topic Zheng et al. [3]. In this connection, the actual state of the urban road network affects the economic development of the city, as well as intercity routes and the region. Since it is established [4-9] that the development of the engineering transport environment has a significant impact on the economic well-being of the city, on the ecological state of the urban environment and, of course, on the health of the population. The study [10-11] of the urban environment allows us to create optimal logistics and transport networks. In the study of this area [12-13] it is important to find the most problematic and vulnerable areas of transport systems, to create the most promising projects for the sustainable development of the city.

As part of the support, control and management of the urban environment, administrative authorities use information technologies that are implemented using geographical information systems (GIS). These GIS take into account all indicators of social comfort, which are based on spatial data about the urban environment. The creation of "smart cities" is based on the transport network, since many social infrastructure objects are linked to transport links, what is shown [14-16]. The development of the "smart cities" system leads to an increase in the quality of social comfort.

The geographic information system (GIS) is increasingly seen as an important component of infrastructure for revenue generation and urban development management, used for real estate identification, verification, taxation, and spatial development management [17].

The use of GIS technologies today is a necessary component for the development of the information component of the socio-economic space; more details are given Boeing [18]. The concept of territorial management applied to the conservation and rational use of natural land will improve the quality of life.

Iyanda [19] experience in using GIS technologies for territory management ensures the effectiveness of increasing tax collection and improving the functions of land and real estate management. Taxation of real estate is a very time-consuming and necessary process that is necessary for both the state and its citizens. Taxable objects are primarily land plots and capital structures that are located on it; linear space objects (roads, engineering objects of pipeline and other systems).

Therefore, it is important for urban areas to create databases about real estate objects. The GIS database must contain spatial information with attribute data describing the height, usage, materials, service relationships, and photos of the territory's features. This data must be presented in the form that was provided so that the system can output property values 
using algorithms that use information in the database. In order to create a tax base, you can define an algorithm for determining tax rates based on information in the database. This process involves a passion for creating taxable real estate rates.

In order to develop territories at the state level, targeted programs are needed based on various sources of information, including databases (fig. 1).

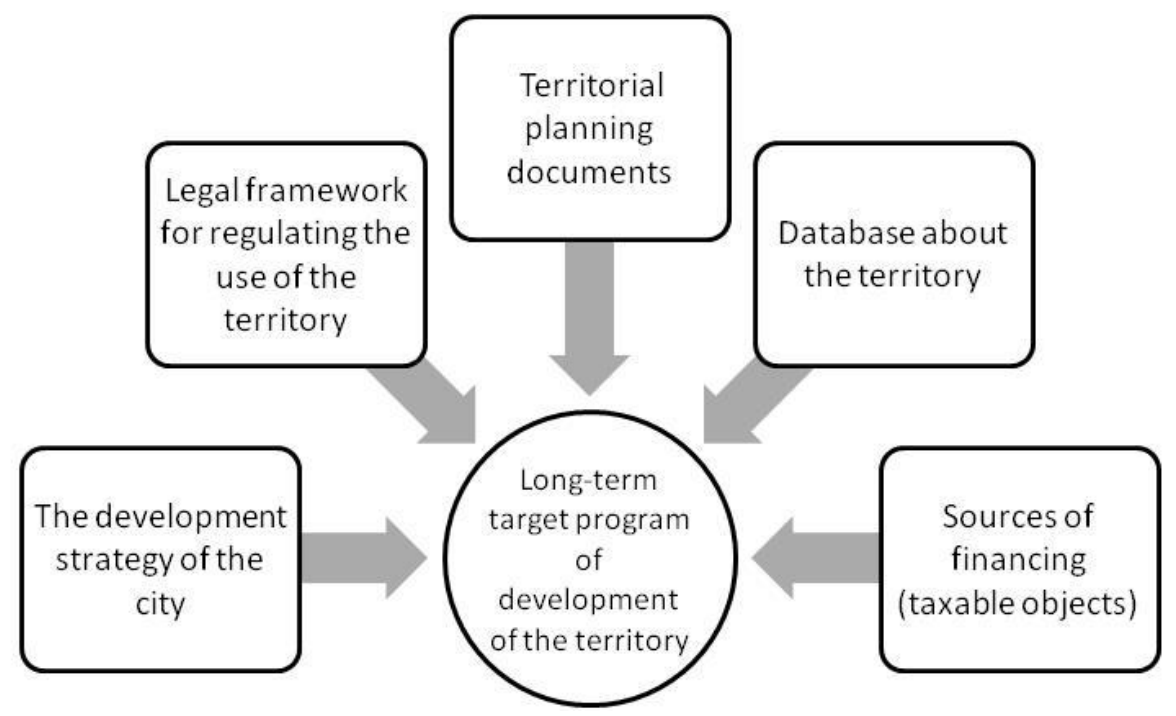

Fig. 1. Scheme sources for the administration of the territory.

Creation and development of GIS databases include digitization of images and printed topographic maps, tablets of urban areas that provide height data in the form of contours and point heights; location of buildings; data on land cover at the landscape level with generalized detail and cadastral data, additional information is provided Zheng et al. [3]. Most of these data sets have a vector format.

Data for filling in the GIS database can be collected using ground-based object data collection, using high-resolution satellite images.

A geographic information system (GIS) is a systematic process of spatial data and processing with attribute data to assess the forecast of changes relative to the current scenario and future growth of a city. Remote sensing (RS) is the collection of data through space or on - Board sensors without any analytical contact with objects. The remote sensing tool and GIS have been studied in many studies on the analysis of urban growth, especially changes in the management of territories, what is shown Jat et al. [20]. Remote sensing is mainly used for analyzing changes in the state of territories [21]. Remote sensing also has a great potential for obtaining detailed and accurate surface information for managing and planning urban areas, what was investigated Jiang et al. [22-23] or Cardillo et al. [24].

Integration of the GIS database with real estate data for management purposes facilitates the use of common address systems, in which the use of a unique number or site identifier number (cadastral number) is associated with user ID numbers. Integration of data from smart city systems about road situations will allow you to more clearly identify problem areas in the engineering and transport infrastructure. For example [25], based on the analysis, determine the location of landfills. The specialization of databases based on information received from smart urban transport systems creates highly intelligent control systems [26].

Therefore, modern GIS programs are one of the best software tools for spatial data analysis that can display attribute data in relation to territory analysis [27]. 
The purpose of the study: to analyze social comfort in terms of engineering and transport infrastructure of the city.

Achieving this research goal involves solving the following tasks:

1. Develop a model for managing data about the urban environment by public authorities.

2. To develop an algorithm for the analysis of the main indicators of assessment of transport infrastructure by using geographic information system.

3. Conduct practical testing on the example of engineering and transport infrastructure of the city.

4. Evaluate the results obtained and identify problem areas of the city's development.

\subsection{Characteristics of the research object}

The city of Tyumen is a major transport hub. It connects the main transport flows of the Western and Eastern directions on the territory of the Russian Federation, including the TRANS-Siberian railway. It is also a connecting transport link with the territories of the Far North of Western Siberia.

The main highways include the Federal highways to Yekaterinburg, Omsk, Surgut, and Kurgan. They also connect the city of Tyumen with almost all districts of the region. The city has two airports "Roshchino" (of Federal significance) and "Plekhanovo" (serving part of local airlines). During the navigation period, the Tura River is used for cargo and passenger transportation.

The main transport characteristics as of 2017 are shown in figure 2.

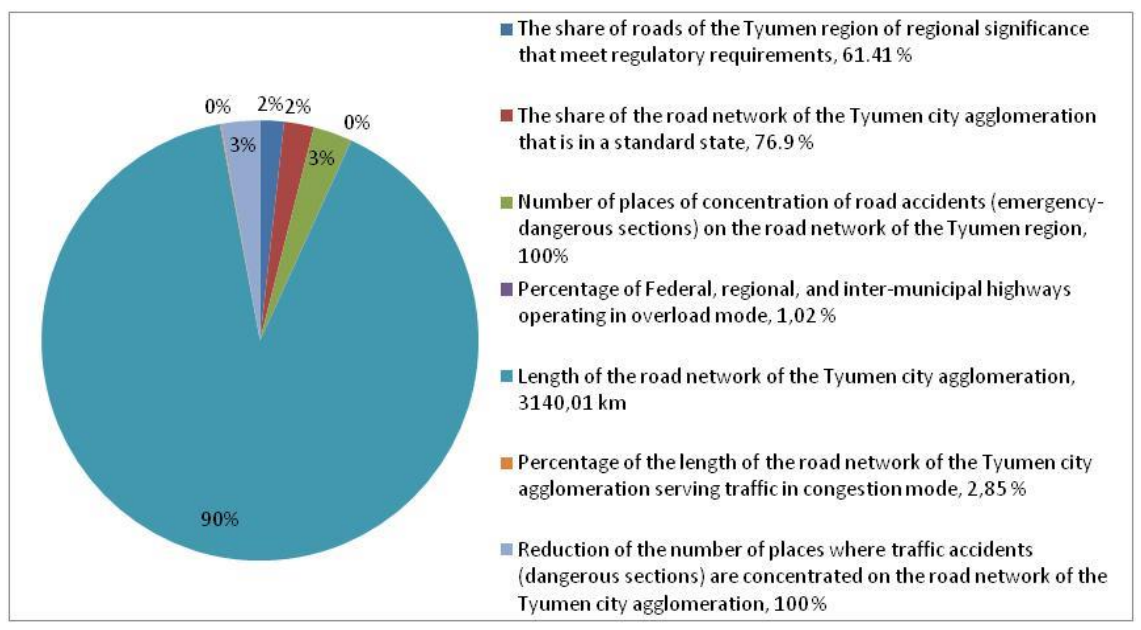

Fig. 2. Indicators of the road network of the Tyumen city agglomeration.

Figure 3 shows the electronic cartographic basis of the city of Tyumen.

The current General plan of the city district of Tyumen plans intensive development of territories within the city boundaries.

It is planned to increase the density of existing buildings in the Central part of the city, along the main planning axes, functional saturation of the Central part of the city, development of previously unused natural areas in order to accommodate low-rise buildings. The development of the city's transport framework implies the creation of stable links between the existing network of streets and the emerging ring system of high-speed highways. 


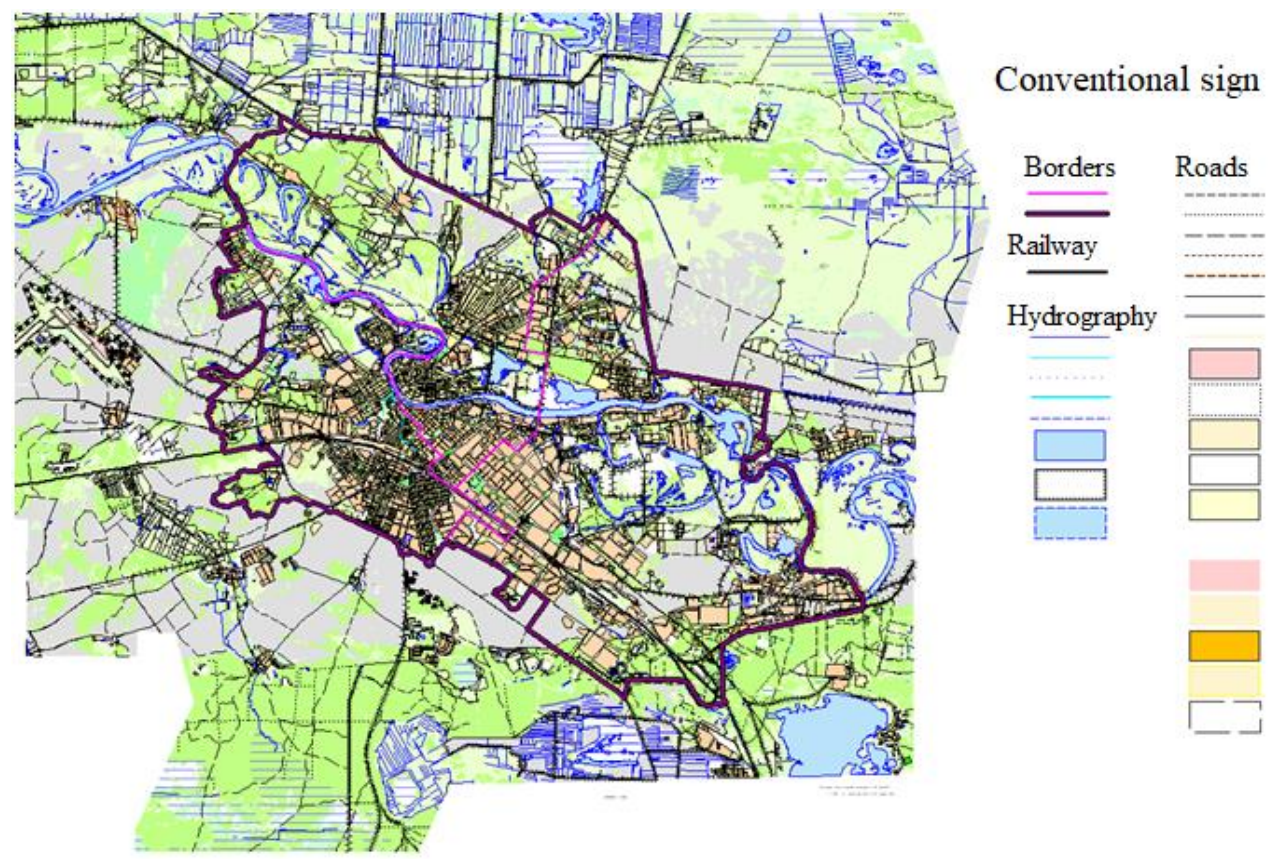

Fig. 3. Map of the city of Tyumen.

A distinctive feature of the city of Tyumen lies in the fact that its geographical location is a transport link not only with the territories of the Far North of Western Siberia, but also Eastern Europe and Northern Asia. Therefore, the city of Tyumen has a high social significance as one of the centers of communication.

\section{Methodology}

The study of the urban environment can be carried out using GIS systems. In this case, to support and solve the problems of the urban environment, we will present a model for managing data about the urban environment authorities figure 4.

The data management model is based on geoinformation analysis. This analysis allows you to create thematic maps of the urban environment with their subsequent assessment and calculation of indicators of social comfort. The engineering and transport infrastructure serves as the basis for the development of the urban agglomeration. Therefore, it is important to evaluate the indicators of such infrastructure in the framework of urban development, what was investigated Sapena et al. [1].

Key indicators for evaluating transport infrastructure:

- walking distance, m;

- transport load, \%;

- bus stops, units;

- transport network, km.

The analysis algorithm is shown in figure 5. 


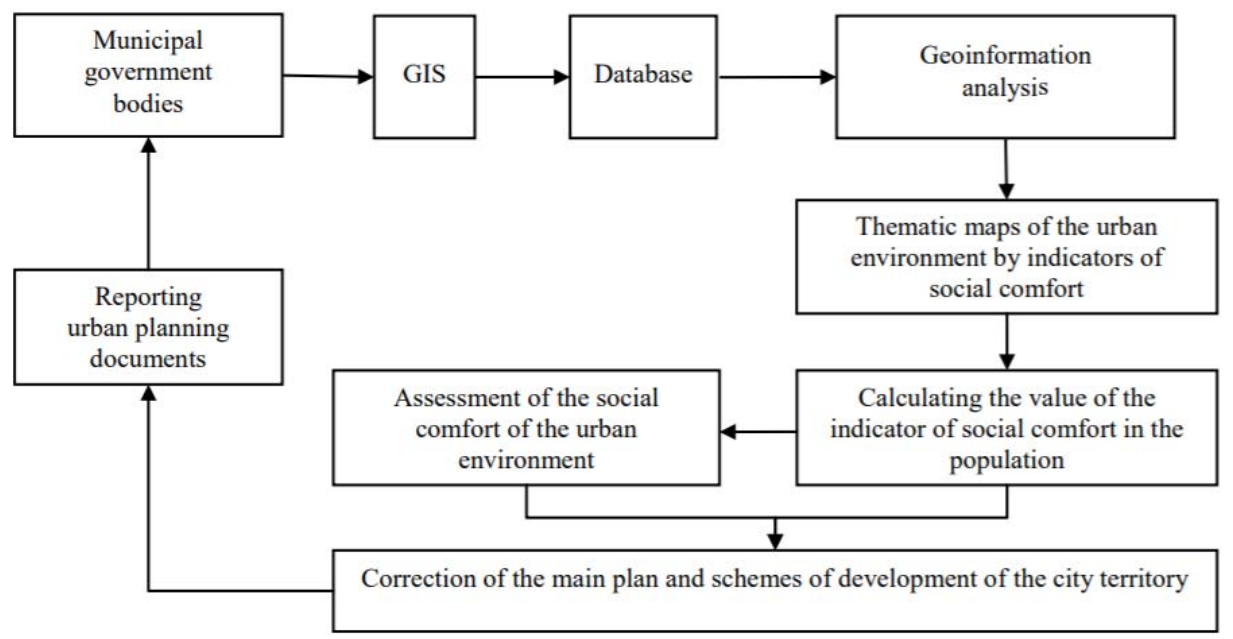

Fig. 4. Model for managing data about the urban environment by public authorities.

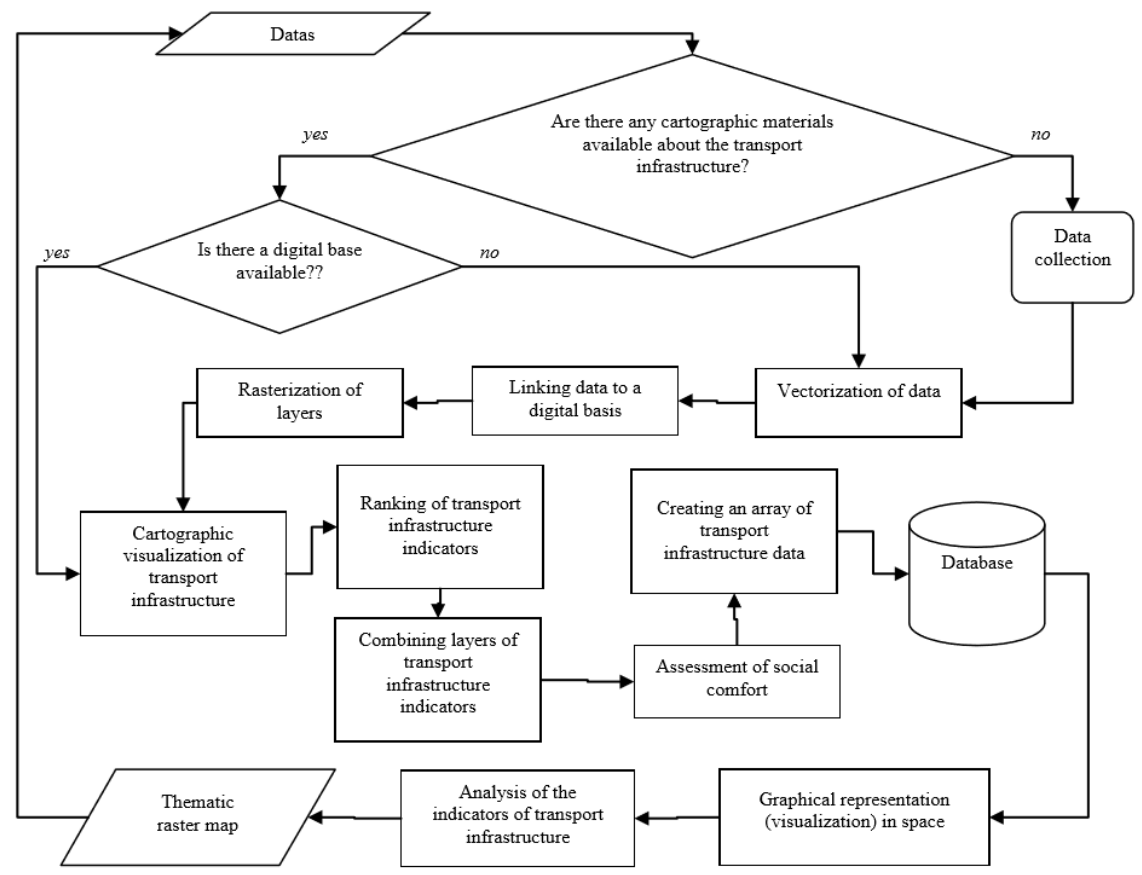

Fig. 5. Analysis algorithm for the main indicators of transport infrastructure assessment.

The result of this algorithm makes it possible to assess the social comfort of the urban agglomeration, its ranking by indicators of transport infrastructure based on the obtained thematic maps. The evaluation principle is to compare the main indicators of transport infrastructure per unit area of an urban area. 


\section{Results and discussion}

As a result of data analysis in the geoinformation program (MapInfo), the main characteristics of the city of Tyumen are established (fig. 6).

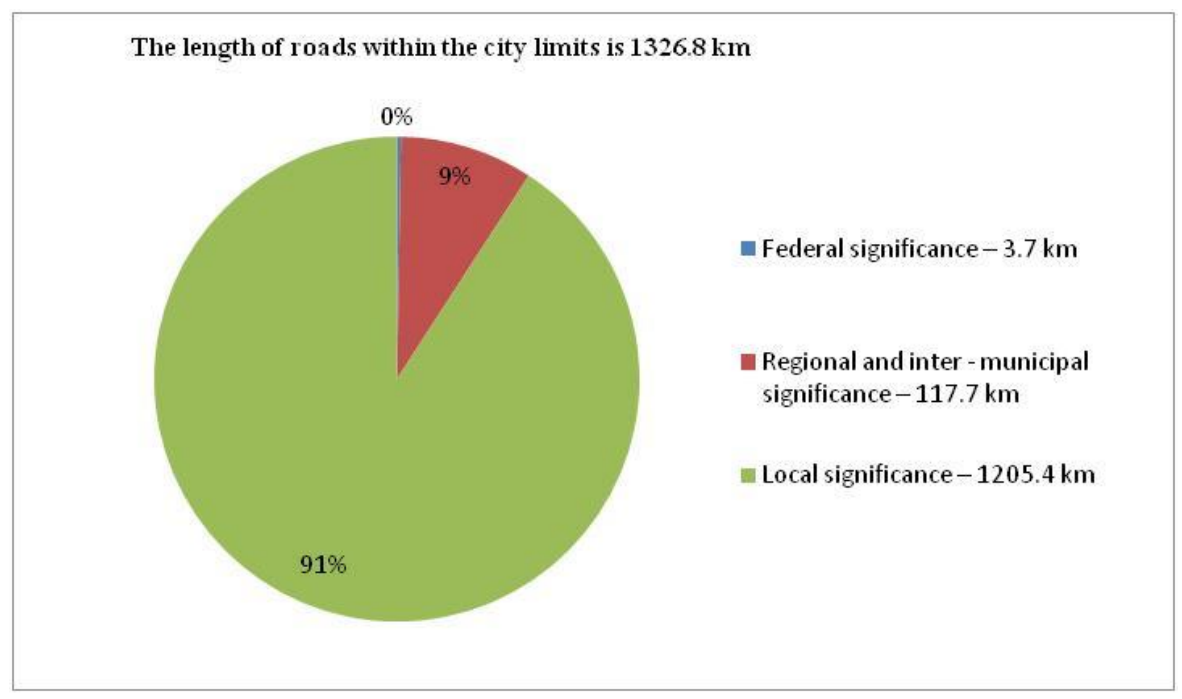

Fig. 6. Characteristics of the city of Tyumen.

The study established numerical characteristics of transport traffic in the city of Tyumen:

- traffic flow is evenly distributed throughout the day, but the main load falls on the morning and evening;

- the main traffic flow is represented by individual cars (approximately $2 / 3$ of the total transport);

- the average speed of traffic flow is about $40-44 \mathrm{~km}$ per hour;

- the load on the main street network is about $90 \%$. If this value is exceeded, there is a congestion of motor vehicles.

The geo-information system MapInfo was used as the basis for geo-analysis.

Stages of analysis of the city's transport infrastructure:

1. Vectorization of data:

- stopping points,

- transport network.

2. The creation of buffer zones with conditions:

- pedestrian accessibility at a distance of $500 \mathrm{~m}$ from the bus stop

- transport load - drawing the main intersections, axes of the main traffic flows.

3. Spatial overlay of the main transport infrastructure objects.

4. The creation of maps of the road infrastructure.

5. Creating an ecological environment of the city based on the transport network

6. Output of the main results and analysis of the obtained data.

During the analysis of the city line, a map of road infrastructure was obtained (fig. 7). 


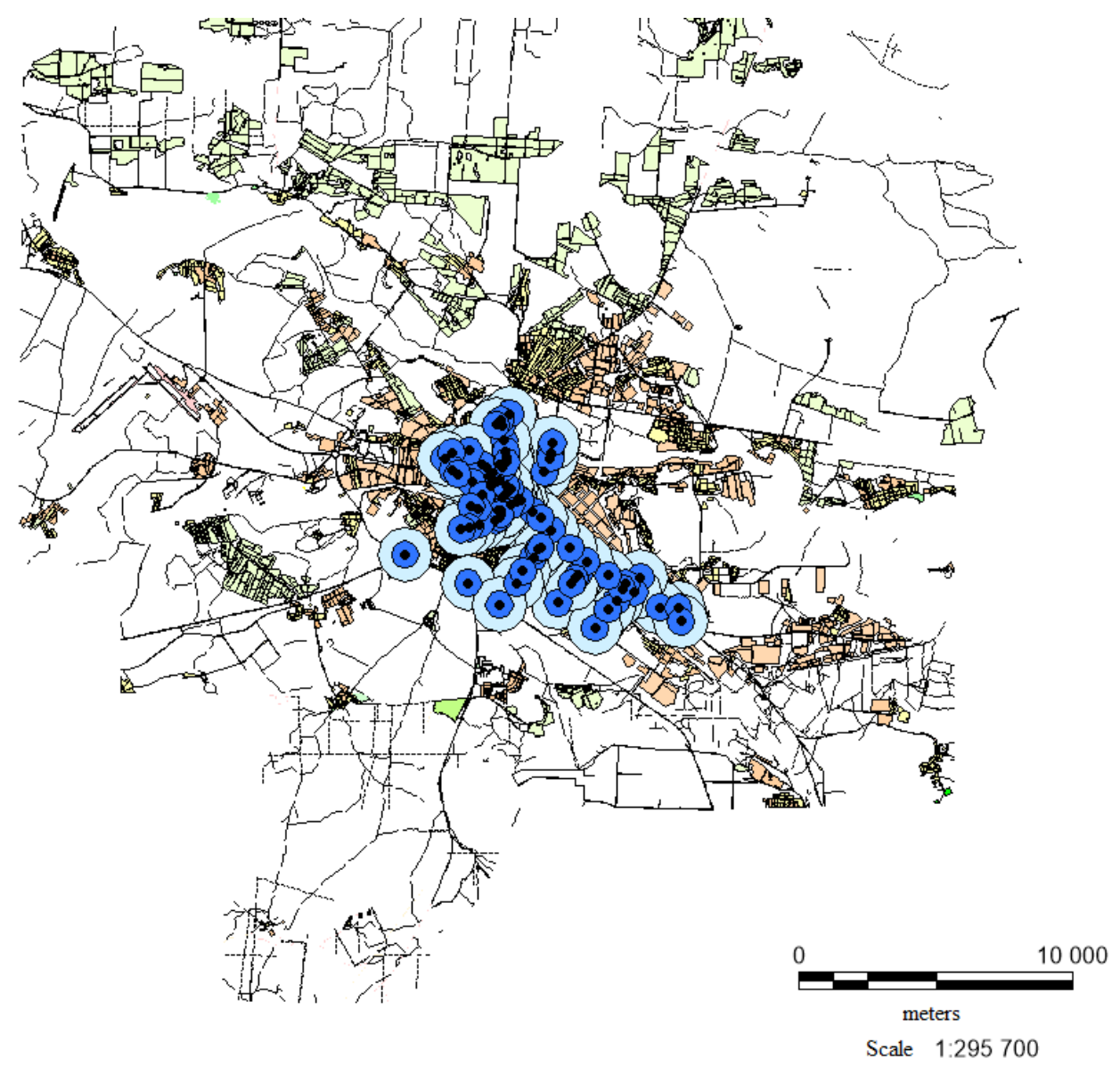

Fig. 7. Map and road infrastructure (shown in the buffer zone of the main traffic load on the road).

The figure 7 shows the main intersections, buffer zones of pedestrian accessibility and the main load centers of the transport network.

Based on the data obtained, an ecological map of the load of the main districts of the city was obtained (fig. 8).

As a result, it was found that the main transport load falls on the city center. This is why the Central part of the city is deteriorating from an environmental point of view.

Buhl et al. [28] carrying out a topological analysis of transport networks by various methods allows us to give the most objective assessment of the current situation. Therefore, scientific developments in the use of graph elements in the construction of street networks are important [28], a structural approach in building a model of transport networks [22-23], in addition, it is worth considering topological models of intersections of street networks [29]. The development of the transport framework and its individual elements is proposed in accordance with the category of city streets and roads established depending on the functions performed. In this aspect Mattsson et al. [30], it is important to take into account the weak and strong points of the city's development. 


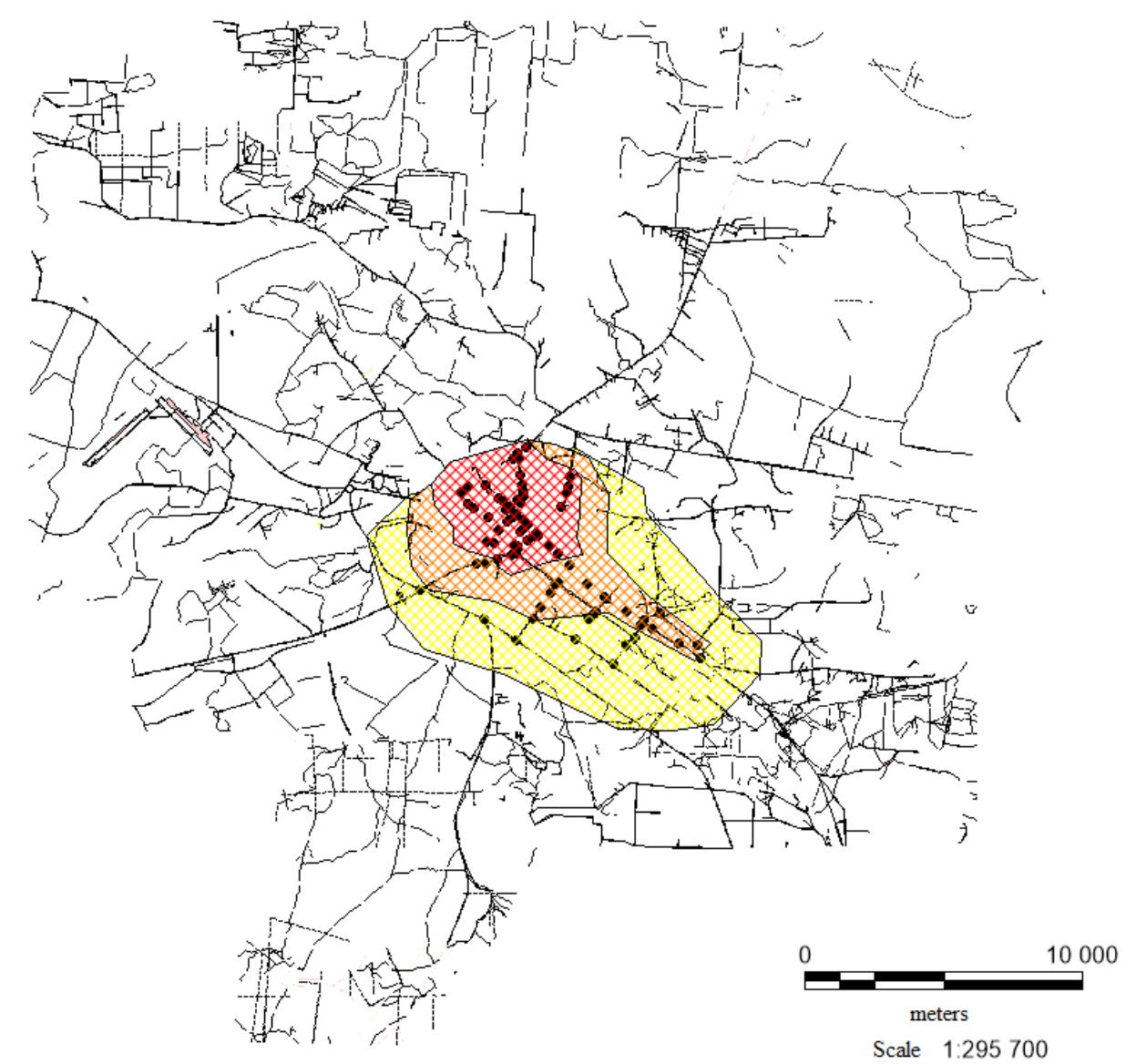

Fig. 8. Ecological map of the load of the main districts of the city of Tyumen.

From an environmental point of view, it is established that the city is subject to the problem of gas contamination, air pollution by exhaust gases [31]. This problem is characterized by a large number of vehicles, low speed of movement, and short transport distances. There is also a tendency to increase traffic density due to an increase in the number of vehicles and the location of the main work places in the city center.

As a result of the analysis, we will highlight the main tasks for the development of urban transport networks to increase the level of social comfort of the population:

- Reduction of travel time in traffic;

- Improving public transport accessibility;

- Improving road safety;

- Expanding the network of Cycling and walking routes;

- Creating Parking lots near public transport stops;

- Development of the local road network and roads in urban areas;

- Equal distribution of jobs in the city;

- Opening of business centers near the city limits;

- Development of the road network in the urban agglomeration (that is, under the city limits to places of outdoor recreation), construction of district roads;

- Economic investment in the engineering and transport network.

The implementation of the analysis algorithm for the main indicators of transport infrastructure assessment based on geoinformation analysis of socio-territorial relations of 
urban infrastructure elements was tested on the territory of a large locality. The obtained data can be implemented both in urban planning and in the economic assessment of land, land management, cadastre, and construction. It is promising to create a geo-information resource that combines all data about the elements of society for each district or territory element.

\section{Conclusions}

Solving traffic flow problems makes it possible to reveal ways, methods, and algorithms for finding optimal conditions with specified criteria for the development of the city territory. By means of modern information systems, you can solve issues related to the uncertainty of the situation, combine the specified criteria, and as a result, predict the options for the development of the situation.

In conclusion, it should be noted that GIS territory management involves the use of new models, algorithms, technologies and methods. In General, the use of GIS technologies changes the system of territory management in order to ensure the rational use of land resources and real estate to create the basis for sustainable development. This creates the need to develop new investment projects for the development of promising territories.

The basis of modern territorial development is the creation of information models with the ability to predict changes. Geospatial information systems are a technological tool for visualizing and analyzing all types of data related to geospatial data. Geographic information systems provide the information basis for all areas of activity. Geoinformation systems also allow you to analyze the possibility of interaction between various objects in space, which makes it possible to objectively assess the dynamics of accounting for changes and forecasts of territorial development.

With the help of various specialized analysis capabilities based on geographic information systems, you can see a large amount of data, get the appropriate map theme, process large amounts of information and visualize it.

The authors would like to thank the Department of road infrastructure and transport Of the Tyumen city administration for their assistance and support in conducting this study.

\section{References}

1. M. Sapena, M. Wurm, H. Taubenböck, D. Tuia, L.A. Ruiz, Computers, Environment and Urban Systems 85 (2020)

2. R.A. El-Rashidy, S.M. Grant-Muller, Journal of Transport Geography, 34, 34-43 (2014)

3. N. Zheng, N. Geroliminis, Transportation Research Part B: Methodological, 57, 326341 (2013)

4. B. Giles-Corti, A. Vernez-Moudon, R. Reis, G. Turrell, et al, The Lancet, 388(10062), 2912-2924 (2016)

5. J. Kerr, J.A. Emond, H. Badland, R. Reis, O. Sarmiento, et al, Environmental health perspectives, 124(3), 290-298 (2016)

6. M.J. Nieuwenhuijsen, Environmental Health: A Global Access Science Source $\mathbf{1 5}$ (2016)

7. W. Mo, Y. Wang, Y. Zhang, D.I. Zhuang, Science of the Total Environment, 574, 1000-1011 (2017) 
8. V.A. Budarova, N.V. Cherezova, A.V. Dubrovskiy, N.G. Martynova, J.D. Medvedeva, Espacios 39(16) (2018)

9. V. Budarova, N. Martynova, V. Budarov, IOP Conference Series: Materials Science and Engineering, 451(1), 012140 (2018)

10. A. Turner, Environment and Planning B: Planning and Design, 34(3), 539-555 (2007)

11. W. Wey, J. Huang, Habitat International, 82, 9-27 (2018)

12. M.A.P.C. Taylor, Growth and Change, 39(4), 593-616 (2008)

13. M.H. Mansourianfar, H. Haghshenas, Cities, 72, 149-159 (2018)

14. C. Badii, P. Bellini, D. Cenni, A. Difino, P. Nesi, M. Paolucci, Future Generation Computer Systems, 75, 14-29 (2017)

15. T. Islam, S.C. Mukhopadhyay, N.K. Suryadevara, IEEE Sensors Journal, 17(3), $577-$ 584 (2017)

16. A. Valdez, M. Cook, S. Potter, Urban Studies, 55(15), 3385-3403 (2018)

17. V. Prasannakumar, H. Vijith, R. Charutha, N. Geetha, Procedia - Social and Behavioral Sciences 2011, 317-325 (2011)

18. G. Boeing, OSMnx: Computers, Environment and Urban Systems, 65, 126-139 (2017)

19. A.E. Iyanda, International Journal of Injury Control and Safety Promotion, 26(1), 72-81 (2019) doi:10.1080/17457300.2018.1476387.

20. M.K. Jat, P.K. Garg, D. Khare, International Journal of Applied Earth Observation and Geoinformation, 10(1), 26-43 (2008)

21. C.P. Lo, D.A. Quattrochi, J.C. Luvall, International Journal of Remote Sensing, 18(2), 287-304 (1997)

22. B. Jiang, C. Claramunt, Environment and Planning B: Planning and Design, 31(1), 151-162 (2004)

23. B. Jiang, C. Claramunt, GeoInformatica, 8(2), 157-171 (2004)

24. A. Cardillo, S. Scellato, V. Latora, S. Porta, Physical Review E - Statistical, Nonlinear, and Soft Matter Physics, 73(6) (2006)

25. N. Chang, G. Parvathinathan, J.B. Breeden, Journal of environmental management, 87(1), 139-153 (2008)

26. A.A. Ganin, A.C. Mersky, A.S. Jin, M. Kitsak, J.M. Keisler, I. Linkov, Transportation Research Part C: Emerging Technologies, 100, 318-329 (2019)

27. A. Pajaziti, O. Tafilaj, Traffic Accidents Analysis with the GPS/Arc/GIS Telecommunication System (2020)

28. J. Buhl, J. Gautrais, N. Reeves, R.V. Solé, S. Valverde, P. Kuntz, G. Theraulaz, European Physical Journal B, 49(4), 513-522 (2006)

29. B. Jiang, Physica A: Statistical Mechanics and its Applications, 384(2), 647-655 (2007)

30. L. Mattsson, E. Jenelius, Transportation Research Part A: Policy and Practice, 81, 1634 (2015)

31. S. Maranghi, M.L. Parisi, A. Facchini, A. Rubino, O. Kordas, R. Basosi, Ecological Indicators 112 (2020) 